\title{
STUDY OF SEGREGATING NATURE IN LIQUID Al-Ga ALLOYS
}

\author{
*I. Koirala, **B.P. Singh and I.S. Jha*** \\ *Central Department of Physics, Tribhuvan University, Kirtipur, Nepal. \\ **University Department of Physics, T.M. Bhagalpur University, India. \\ ***M.M.A.M. Campus, Biratnagar, Tribhuvan University, Nepal.
}

\begin{abstract}
We report energetic of mixing behavior of liquid Al-Ga alloys, using simple statistical theory through concentration dependence thermodynamic, structural, transport and surface properties at $1023 \mathrm{~K}$. The concentration dependent thermodynamic functions (free energy of mixing, enthalpy of mixing, entropy of mixing and activity coefficient of the component), structural functions (concentration fluctuation in the long wavelength limit and chemical short range order parameter), transport properties (diffusivity and viscosity) and surface properties (surface segregation and surface tension) have got special attention to show a tendency of homo-coordination of atom in the mixture. The theoretical analysis reveals that input parameter, order energy is temperature dependent and $\mathrm{Al}-\mathrm{Ga}$ alloys is of weakly interacting system.
\end{abstract}

Keywords: Simple statistical theory; Liquid alloy; Order energy; Structural functions; Surface segregation.

\section{INTRODUCTION}

Liquid alloys are disorder system with short range order and exhibit a significant variety of atomic structures. The various properties of the alloys in the melt are helpful to understand the alloying behaviour in the solid state which is of immense important in metallurgical science for preparing metal alloys. Due to the strong correlation among the atoms and their state of disorder, the formulation of exact theory of liquid alloy to understand thermodynamic and structural properties, arises a problem of mathematical complexity. It is much more difficult to understand the properties of disordered material like liquid alloys as compared to those of crystal (Adhikari et al.2012). Many experimentalists ( Hultgren et al. 1973; Saboungi et al.1978; Lamparter et al.1984; Harada et al.1988; Iida \& Guthrie,1988) as well as theoreticians ( Flory, 1942; Lebowitz, 1964; Harrision, 1966; Faber, 1972; Bhatia et al. 1973; Shimoji, 1977; Alonso \& March, 1982; Bernu et al. 1987; Singh, 1987; Li \& Tosi, 1989; Singh et al. 1990, 1993; Anusionwu, 2002; Novakovic, 2010; Adhikari et al.2012; Koirala et al. 2013) have long been trying to interpret the alloying nature of liquid alloys. The concentration dependent properties of liquid alloys, basically thermodynamic and structural, can provide enormous amount of information for understanding metallurgical process and material preparation of the metal alloys. Thermodynamic properties help to know the stability and bonding strength of different constituents in the alloys. The structural properties are useful in obtaining the microscopic information on structure of molten alloys. The ordering and phase separation behavior of molten alloys and the nature of transition from fluid phase to the glassy state can be explained on the basis of these structural functions.

In metallurgical science, metal alloys are generally beneficial over metals for their increased mechanical strength, heat resistance, chemical resistance, and decreased production costs. Aluminium and aluminium alloys have many outstanding attributes that lead to a wide range of applications, including good corrosion and oxidation resistance, high electrical and thermal conductivities, low density, high reflexivity, high ductility and reasonably high strength and relatively low cost. Aluminium alloys are non-toxic and easiest to recycle among the structural materials (Campbell 2008). Aluminium has a large negative free energy with strong oxide formation capacity. It, therefore, has thermodynamic ability to split water. The liquid AlGa alloys spontaneously produce hydrogen if mixed with water. This technology could be used to generate hydrogen on demand and hence unnecessary storage of hydrogen is not required (Woodall 2007).

In the present work we intend to explain the alloying behavior of aluminium-gallium liquid on the basis of simple statistical model. It is a statistical mechanical model in which the grand partition function is used to obtain analytical expressions for the conditional probabilities enumerating the occupation of two neighbouring sites by the atoms of the constituent elements in terms of the ordering energy (Singh et al.1990). The ordering energy, an important input parameter, is used for all calculations which is temperature dependent. The observed thermodynamic

Author for Correspondence: Ishwar Koirala, Central Department of Physics, Tribhuvan University, Kirtipur, Nepal. E-mail: ishwar_koirala@yahoo.com. 
properties of mixing (free energy of mixing, enthalpy of mixing and entropy of mixing) of Al-Ga alloys at $1023 \mathrm{~K}$ are symmetrical about equiatomic composition(Hultgren et al.) and the value of concentration fluctuation in long wavelength limit which is calculated from the activity data (Hultgren et al.) shows that the alloys is segregating in nature even though atomic mismatch $\left(\mathrm{V}_{\mathrm{Ga}} / \mathrm{V}_{\mathrm{Al}}=\right.$ $1.18)$ and electronegativity difference $(=0.20)$ are not significantly large.

Paper outlines are as follows: In section 2, general formalism about the theory is presented. Section 3 deals with the result and discussion and conclusion are presented in section 4 .

\section{METHODOLOGY}

In the simple statistical model a grand partition function is constructed to deduce the relation for thermodynamic and structural functions.

\section{Thermodynamic functions}

The grand partition function for simple binary liquid alloys consisting of $\mathrm{N}_{\mathrm{A}}(=\mathrm{Nc})$ number of $\mathrm{A}$ atoms and $\mathrm{N}_{\mathrm{B}}(=\mathrm{N}(1-\mathrm{c}))$ number of $\mathrm{B}$ atoms can be generalized as

$\Xi=\sum_{\mathrm{E}} \mathrm{q}_{\mathrm{A}}^{\mathrm{N}_{\mathrm{A}}}(\mathrm{T}) \mathrm{q}_{\mathrm{B}}^{\mathrm{N}_{\mathrm{B}}}(\mathrm{T}) \exp \left(\frac{\mu_{\mathrm{A}} \mathrm{N}_{\mathrm{A}}+\mu_{\mathrm{B}} \mathrm{N}_{\mathrm{B}}-\mathrm{E}}{\mathrm{k}_{\mathrm{B}} \mathrm{T}}\right)$

Where $\mathrm{q}_{\mathrm{i}}^{\mathrm{N}_{\mathrm{i}}}$ are the partition functions of atoms ( $\mathrm{i}=\mathrm{A}$ or $\mathrm{B})$ associated with inner and vibrational degree of freedom. $\mathrm{q}_{\mathrm{i}}$ the same whether the atom $\mathrm{i}$ is located in the pure state or in alloy. $\mu_{\mathrm{A}}$ and $\mu_{\mathrm{B}}$ are the chemical potentials and $\mathrm{E}$ is the configurational energy, $\mathrm{k}_{\mathrm{B}}$, the Boltzmann constant, c, the concentration of the component and $\mathrm{T}$, absolute temperature (Singh et al.1990). The standard thermodynamic relation for free energy of mixing is

$\mathrm{G}_{\mathrm{M}}=\mathrm{G}_{\mathrm{M}}^{\mathrm{id}}+\mathrm{G}_{\mathrm{M}}^{\mathrm{XS}}$

where

$$
\mathrm{G}_{\mathrm{M}}^{\mathrm{id}}=\mathrm{RT}\{\mathrm{cInc}+(1-\mathrm{c}) \operatorname{In}(1-\mathrm{c})\}
$$

And

$$
\begin{aligned}
\mathrm{G}_{\mathrm{M}}^{\mathrm{Xs}} & =\int_{0}^{\mathrm{c}} \operatorname{In} \sigma^{\mathrm{z}} \mathrm{dc} \\
& =\mathrm{RT}\left\{\mathrm{cIn} \gamma_{\mathrm{A}}+(1-\mathrm{c}) \operatorname{In} \gamma_{\mathrm{B}}\right\}
\end{aligned}
$$

with

$$
\begin{aligned}
& \sigma=(\beta+2 \mathrm{c}-1) \exp \left(-\omega / \mathrm{zk}_{\mathrm{B}} \mathrm{T}\right) / 2 \mathrm{c} \\
& \gamma_{\mathrm{A}}=[(\beta-1+2 \mathrm{c}) / \mathrm{c}(1+\beta)]^{\mathrm{z} / 2} \\
& \gamma_{\mathrm{B}}=[(\beta+1-2 \mathrm{c}) /(1-\mathrm{c})(1+\beta)]^{\mathrm{z} / 2}
\end{aligned}
$$

$$
\beta=\left\{1+4 \mathrm{c}(1-\mathrm{c})\left[\exp \left(2 \omega / \mathrm{zk}_{\mathrm{B}} \mathrm{T}\right)-1\right]\right\}^{1 / 2}
$$

For the equiatomic composition ( $\mathrm{c}=\frac{1}{2}$ ), relation (4) reduces to

$$
\frac{\mathrm{G}_{\mathrm{M}}^{\mathrm{XS}}}{\mathrm{RT}}=\ln 2^{\mathrm{z} / 2}\left[1+\exp \left(-\omega / \mathrm{zk}_{\mathrm{B}} \mathrm{T}\right)\right]^{-\mathrm{z} / 2}
$$

Using the relations (2),(3) and (4), the free energy of mixing will be

$$
\begin{aligned}
\mathrm{G}_{\mathrm{M}} & =\mathrm{RT}\left[\mathrm{cInc}+(1-\mathrm{c}) \operatorname{In}(1-\mathrm{c})+\mathrm{cIn} \gamma_{\mathrm{A}}+(1-\mathrm{c}) \gamma_{\mathrm{B}}\right] \\
& =\operatorname{RT}\left[\mathrm{c} \ln \mathrm{c}+(1-\mathrm{c}) \ln (1-\mathrm{c})+\mathrm{c}(1-\mathrm{c}) \frac{\omega}{\mathrm{k}_{\mathrm{B}} \mathrm{T}}\right]
\end{aligned}
$$

The heat of mixing $\left(\mathrm{H}_{\mathrm{M}}\right)$ can be obtained from the standard thermodynamic expression as

$$
\begin{aligned}
\mathrm{H}_{\mathrm{M}} & =\mathrm{G}_{\mathrm{M}}-\mathrm{T}\left(\frac{\partial \mathrm{G}_{\mathrm{M}}}{\partial \mathrm{T}}\right)_{\mathrm{C}, \mathrm{P}, \mathrm{N}} \\
& =\mathrm{RT}\left[\mathrm{c}(1-\mathrm{c}) \frac{\omega}{\mathrm{k}_{\mathrm{B}} \mathrm{T}}-\mathrm{c}(1-\mathrm{c}) \frac{1}{\mathrm{k}_{\mathrm{B}}} \frac{\mathrm{d} \omega}{\mathrm{dT}}\right]
\end{aligned}
$$

and entropy of mixing $\left(\mathrm{S}_{\mathrm{M}}\right)$ is also obtained from the relation

$$
\mathrm{S}_{\mathrm{M}}=\left(\mathrm{H}_{\mathrm{M}}-\mathrm{G}_{\mathrm{M}}\right) / \mathrm{T}
$$

The activity of binary liquid alloys, $\mathrm{a}_{\mathrm{i}}(\mathrm{i}=\mathrm{A}$ or $\mathrm{B})$, can be related to the free energy of mixing by the relation

$\mathrm{RT} \ln \mathrm{a}_{\mathrm{i}}=\mathrm{G}_{\mathrm{M}}+\left(1-\mathrm{c}_{\mathrm{i}}\right)\left(\frac{\partial \mathrm{G}_{\mathrm{M}}}{\partial \mathrm{c}_{\mathrm{i}}}\right)_{\mathrm{T}, \mathrm{P}, \mathrm{N}}$

Then we have from Eq. (6),

$$
\begin{aligned}
& \ln a_{A}=\ln c+(1-c)^{2} \frac{\omega}{k_{B} T} \\
& \ln a_{B}=\ln (1-c)+c^{2} \frac{\omega}{k_{B} T}
\end{aligned}
$$

\section{Structural Properties}

Concentration fluctuations in the long wavelength limit $\left(\mathrm{S}_{\mathrm{cc}}(0)\right)$ is an essential structural function which has been widely used to study the nature of atomic order in binary liquid alloys (Bhatia et al.1973). $\mathrm{S}_{\mathrm{cc}}(0)$ is thermodynamically related to experimental activity of each component by the standard relations given as

$\mathrm{S}_{\mathrm{cc}}(0)=(1-\mathrm{c})\left(\frac{\partial \ln \mathrm{a}_{\mathrm{A}}}{\partial \mathrm{c}}\right)^{-1}$

$=\mathrm{c}\left(\frac{\partial \ln \mathrm{a}_{\mathrm{B}}}{\partial(1-\mathrm{c})}\right)^{-1}$

Theoretically $\mathrm{S}_{\mathrm{cc}}(0)$ can be evaluated from eq.(6) through standard relation given below 


$$
\begin{aligned}
& S_{c c}(0)=R T\left(\frac{\partial^{2} G_{M}}{\partial c^{2}}\right)_{T, P, N}^{-1} \\
& =c(1-c)\left[1+\frac{z}{2 \beta}(1-\beta)\right]^{-1}
\end{aligned}
$$

When the ordering energy is zero, Eq.(12) reduces to

$\operatorname{Scc}(0)=c(1-c)=\operatorname{Scc}(0, i d)$

Owing to difficulties in diffraction experiments, the theoretical determination of $\mathrm{S}_{\mathrm{cc}}(0)$ is of great importance when the nature of atomic interactions in the melt has to be analysed. The mixing behaviour of liquid alloys can be deduced from the deviation of $S_{\text {cc }}(0)$ from the ideal value, $\mathrm{S}_{\mathrm{cc}}(0$, id $) . \mathrm{S}_{\mathrm{cc}}(0)<\mathrm{S}_{\mathrm{cc}}(0$, id $)$ indicates that the chemical order prefers hetero-pairs, whereas if $\mathrm{S}_{\mathrm{cc}}(0)$ $>\mathrm{S}_{\mathrm{cc}}(0$, id $)$, the chemical order leads to a preference of homo-pairs.

Chemical short range order parameter $\alpha_{1}$ is another important structural function, which gives insight into the local arrangement of the atoms in the molten alloys (Cowley 1950,Warren 1969). It is difficult to obtain the experimental values of $\alpha 1$, because of difficulties in diffraction experiment but theoretical values of this parameter are easily obtain via conditional probability $[\mathrm{A} / \mathrm{B}]$ which defines the probability of finding an Aatom as a nearest neighbor of a given B-atom (Cowley 1950,Warren 1969). To quantify the degree of order in the molten alloys $\alpha_{1}$ can be evaluated theoretically:

$$
\frac{\mathrm{S}_{\mathrm{cc}}(0)}{\mathrm{c}(1-\mathrm{c})}=\frac{1+\alpha_{1}}{1-(\mathrm{z}-1) \alpha_{1}}
$$

where $\mathrm{z}$ is the coordination number, which is taken as 10 for our purposes. We note that varying the value of $z$ does not have any effect on the position of the minima of $\alpha_{1}$. The knowledge of the CSRO parameter provides an immediate insight into the nature of the local arrangement of atoms in the mixture. For the equiatomic composition, the CSRO parameter is found to be $-1 \leq$ $\alpha_{1} \geq 1$.The negative values of $\alpha_{1}$ indicate ordering in the melt, which is complete if $\alpha_{1}=-1$. On contrary, positive values of $\alpha_{1}$ indicate segregating, leading to phase separation if $\alpha_{1}=1$.

\section{Transport properties}

The transport properties such as viscosity, chemical diffusion coefficients etc may help to gain knowledge about the mixing behaviour of binary liquid alloys at the microscopic level. Viscosity ( $\eta$ ) of liquid alloys is equally important in the understanding of the atomic level structure and interactions. As in the case of thermodynamic functions, the composition dependence of viscosity of liquid alloys is also found to exhibit either a linear variation, or positive or negative deviations from the linear law. A simple formula for the investigation of viscosity of a binary solution is

$\eta=\eta_{\text {id }}\left[1-c(1-c)\left(\frac{2 \omega}{\mathrm{k}_{\mathrm{B}} \mathrm{T}}\right)\right]$

But, $\quad \eta_{\text {id }}=\mathrm{c} \eta_{\mathrm{A}}^{0}+(1-\mathrm{c}) \eta_{\mathrm{B}}^{0}$

where $\eta_{i}^{0}$ is the viscosity of pure component $i$ $(\mathrm{i}=\mathrm{A}, \mathrm{B}) ; \omega$ is the interchange energy or order energy; $\mathrm{c}$, the concentration of the component; $\mathrm{kB}, \mathrm{T}$ are Boltzmann constant and absolute temperature(MoelevynHughes, 1964).

The mixing behaviour of the alloy forming molten metals can also be studied at the microscopic level in terms of coefficient of diffusion. The mutual diffusion coefficient $\left(D_{M}\right)$ of binary liquid alloys can be expressed in terms of activity $\left(f_{i}\right)$ and intrinsic diffusion coefficient $\left(D_{i d}\right)$ of an ideal mixture with the help of Darken's equation (Darken, 1953).

$$
\frac{D_{M}}{D_{\text {id }}}=\frac{d \ln f_{i}}{d x_{i}}
$$

Considering only the energetics of the nearest- neighbour bond, we obtain an expression for

$$
D_{M} \frac{D_{M}}{D_{i d}}=\left[1-c(1-c)\left(\frac{2 \omega}{k_{B} T}\right)\right]
$$

with

$$
\mathrm{D}_{\mathrm{M}}=\mathrm{c} \mathrm{D}_{\mathrm{B}}+(1-\mathrm{c}) \mathrm{D}_{\mathrm{A}}
$$

where $\mathrm{D}_{\mathrm{A}}$ and $\mathrm{D}_{\mathrm{B}}$ are the self-diffusion coefficients of pure components A and B respectively.

The ratio $D_{M} / D_{\text {id }}$ indicates the mixing nature of molten alloys; $\mathrm{D}_{\mathrm{M}} / \mathrm{D}_{\text {id }}<1$ indicates the tendency of homocoordination while $\mathrm{D}_{\mathrm{M}} / \mathrm{D}_{\text {id }}>1$ indicates the tendency of hetero-coordination and $\mathrm{D}_{\mathrm{M}} / \mathrm{D}_{\mathrm{id}}$ approaches 1 for ideal mixing.

\section{Surface properties}

For the processing of materials and productions in the metallurgical industry, knowledge of surface phenomena like surface segregation and surface tension is essential. On the basis of assumption of monatomic surface layer, Butler's approach (Butler, 1932) of surface tension $\tau$ of liquid solution can be expressed as

$\tau=\frac{\mu_{\mathrm{A}}^{\mathrm{s}}-\mu_{\mathrm{A}}^{\mathrm{b}}}{\alpha_{\mathrm{A}}}=\frac{\mu_{\mathrm{B}}^{\mathrm{s}}-\mu_{\mathrm{B}}^{\mathrm{b}}}{\alpha_{\mathrm{B}}}=\ldots \ldots . .=\frac{\mu_{\mathrm{i}}^{\mathrm{s}}-\mu_{\mathrm{i}}^{\mathrm{b}}}{\alpha_{\mathrm{i}}}$

Where $\mu_{i}^{\mathrm{s}}, \mu_{\mathrm{i}}^{\mathrm{b}}$ and $\alpha_{\mathrm{i}}$ represent respectively the chemical potential in the hypothetical surface and that in the bulk and molar surface area of pure component i (A or B). 
Equation(20) yields the expressions for surface tension in terms of partial excess free energy of mixing in bulk( $\left.G_{i}^{E, b}\right)$ and at the surface $\left(G_{i}^{E, s}\right)$ and concentration in the bulk(c) and at the $\operatorname{surface}\left(\mathrm{c}^{\mathrm{s}}\right)$ as

$$
\begin{aligned}
& \tau=\tau_{A}+\frac{1}{\alpha_{A}}\left(G_{A}^{E, S}-G_{A}^{E, b}\right) \\
&+\frac{R T}{\alpha_{A}} \operatorname{Inc} s-\frac{R T}{\alpha_{A}} \operatorname{Inc} \\
& \tau=\tau_{B}+\frac{1}{\alpha_{B}}\left(G_{B}^{E, s}-G_{B}^{E, b}\right) \\
&+\frac{R T}{\alpha_{B}} \operatorname{In}\left(1-c^{s}\right)-\frac{R T}{\alpha_{B}} \operatorname{In}(1-c)
\end{aligned}
$$

where $\tau_{A}$ and $\tau_{B}$ are surface tension of pure component $\mathrm{A}$ and $\mathrm{B}$ respectively.

The area of monatomic surface layer for the component i can be calculated by the relation (Butler,1932).

$$
\alpha_{i}=1.091 \mathrm{~N}_{0}^{1 / 3} \Omega_{\mathrm{i}}^{2 / 3}
$$

Where $\mathrm{N}_{0}$ is Avogadro's number and $\Omega_{\mathrm{i}}$ stands for molar volume of the component $i$, can be calculated from its molar mass and density.

\section{RESULT AND DISCUSSION}

The basic inputs for the computation of the thermodynamic properties for binary liquid alloys are energy parameters, i.e. $\omega$ and $d \omega / d T$. With the experimental value (Hultgren 1973) of excess free energy of mixing $\left(G_{M}^{X} \mathrm{~s}\right)$ and heat of mixing $\left(\mathrm{H}_{\mathrm{M}}\right)$ for equiatomic composition ( $\mathrm{c}=1 / 2)$ such energy parameters have been determined using the equations (5) and (7). The best fitted value of the parameters for the alloy Al$\mathrm{Ga}$ at $1023 \mathrm{~K}$ are found as

$$
\omega=0.0132 \mathrm{eV} \text { and } \frac{\mathrm{d} \omega}{\mathrm{dT}}=-2.208 \times 10^{-24} \mathrm{JK}^{-1}
$$

The estimated energy parameter $(\omega)$ is found to small and positive, which suggests that there is higher tendency for like atoms to pair in the alloy which implies a homo-coordination system. We have observed that if energy parameters are supposed to be independent of temperature $(\mathrm{d} \omega / \mathrm{dT}=0)$, then $\mathrm{S}_{\mathrm{M}}$ and $\mathrm{H}_{\mathrm{M}}$ so obtained are in poor agreement with experimental data. This suggests the importance of temperature dependence ordering energy, $\omega$.

The free energy of mixing and entropy of mixing for AlGa liquid alloy at $1023 \mathrm{~K}$ have been computed from equations (6) and (8). The plot of $\frac{G_{M}}{R T}$ and $\frac{S_{M}}{R}$ versus cAl are depicted in figure 1. Fig. 1 shows that theoretical and

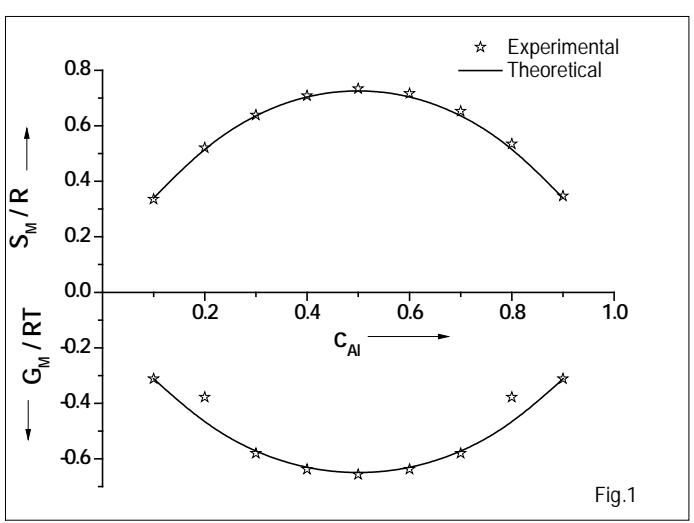

Figure 1: Free energy of mixing $\left(G_{M}\right)$ and entropy of mixing $\left(S_{M}\right)$ Vs concentration of aluminium $\left(c_{A l}\right)$ in liquid Al-Ga alloy at $1023 \mathrm{~K}$.

experimental values of $\frac{G_{M}}{R T}$ and $\frac{S_{M}}{R}$ are in good agreement in all concentrations of aluminium. is $\frac{G_{M}}{R T}$ minimum but $\frac{\mathrm{S}_{\mathrm{M}}}{\mathrm{R}}$ maximum at $\mathrm{c}_{\mathrm{Al}}=0.5$, which show that Al-Ga liquid alloy is symmetric about equiatomic concentration. The plot of $\mathrm{H}_{\mathrm{M}} / \mathrm{RT}$ verses $\mathrm{c}_{\mathrm{Al}}$ depited in fig. 2 also shows that the calculated values of $\mathrm{H}_{\mathrm{M}} / \mathrm{RT}$ are in good agreement with its experimental values and the alloys is symmetric about equiatomic composition. Positive deviations from Raoultian behaviour was observed in the thermodynamic properties of liquid Al-Ga alloys.

We have used the same value of the energy parameter $\omega$ in Eq. 9(a) and 9(b) for the evaluation of chemical activities of the components of the alloy. There is well agreement between theoretical and experimental values of the activities of the components $\mathrm{Al}$ and $\mathrm{Ga}$ of the alloys (Hultgren et al.).

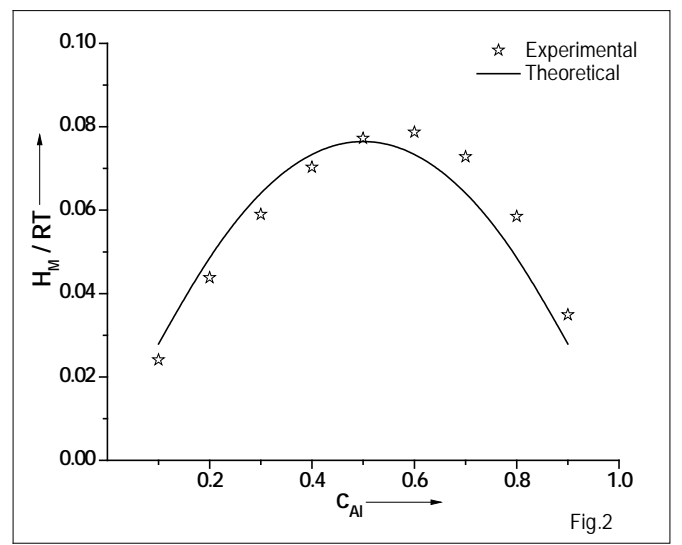

Figure 2: Heat of mixing $\left(\mathrm{H}_{\mathrm{M}}\right)$ Vs concentration of aluminium $\left(\mathrm{C}_{\mathrm{Al}}\right)$ in liquid Al-Ga alloy at $1023 \mathrm{~K}$.

We have used Eq. (12) to compute the $\mathrm{S}_{\mathrm{cc}}(0)$ for Al-Ga. Figure 4 shows a plot of the calculated and experimental values of $\mathrm{S}_{\mathrm{cc}}(0)$ along with the ideal values. The calculated values of $\mathrm{S}_{\mathrm{cc}}(0)$ are in good agreement with the experimental values of $\mathrm{S}_{\mathrm{cc}}(0)$. The computed $\mathrm{Scc}(0)$ nearly attain ideal values, i.e. Al-Ga exhibits ideal behaviour for the composition $0 \leq \mathrm{c}_{\mathrm{Al}} \leq 0.2$ and 0.8 
$\leq \mathrm{c}_{\mathrm{Al}} \leq 1$. But in the region $0.2<\mathrm{c}_{\mathrm{Al}}<0.8$, the computed $\operatorname{Scc}(0)$ are greater than ideals values. The result can be used to understand the nature of atomic order in binary liquid alloys. In figure 4 , it is seen that $\mathrm{S}_{\mathrm{cc}}(0)>\mathrm{S}_{\mathrm{cc}} \mathrm{id}(0)$, which shows that liquid alloys $\mathrm{Al}-\mathrm{Ga}$ at $1023 \mathrm{~K}$ is of segregating in nature.

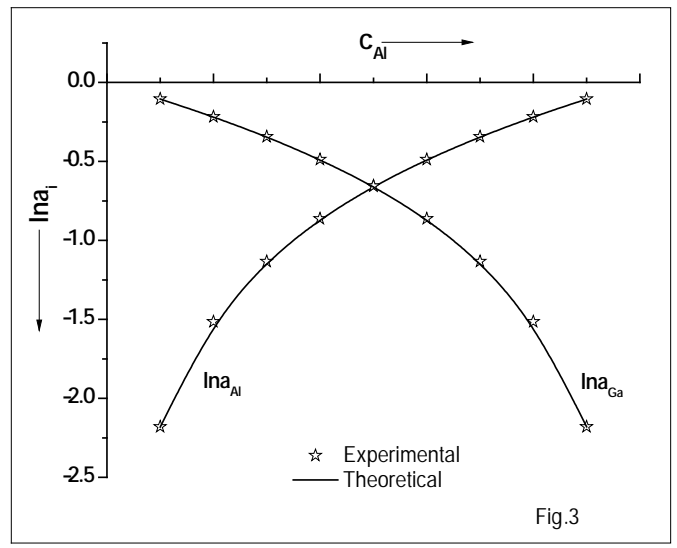

Figure 3: Chemical activity $\left(a_{i}\right)$ Vs concentration of aluminium $\left(\mathrm{C}_{\mathrm{Al}}\right)$ in liquid Al-Ga alloy at $1023 \mathrm{~K}$.

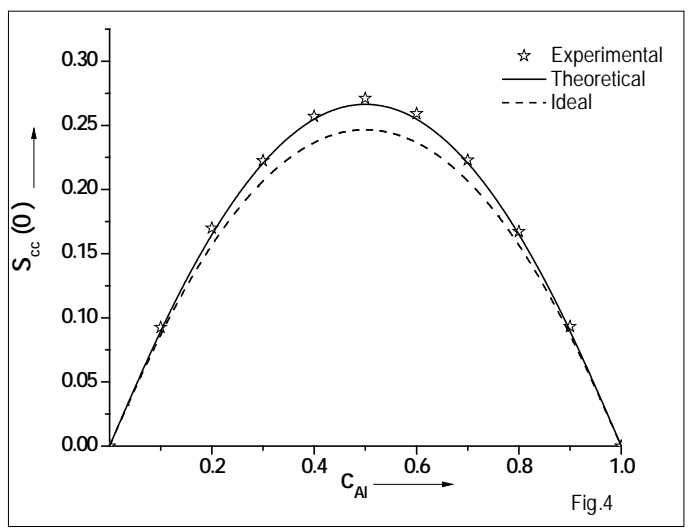

Figure 4: Concentration fluctuation at long wavelength limit $\left(\mathrm{S}_{\mathrm{cc}}(0)\right) \mathrm{Vs}$ concentration of aluminium $\left(\mathrm{C}_{\mathrm{Al}}\right)$ in liquid Al-Ga alloy at $1023 \mathrm{~K}$.

The knowledge of CSRO parameter $\alpha_{1}$ provides an immediate insight into the nature of the local arrangement of atoms in the mixture. Figure 5 shows the plots of $\alpha_{1}$ against chemical composition, obtained from Eq.(14) for Al-Ga at 1023K. The positive values of $\alpha_{1}$ throughout whole concentration range of $\mathrm{Al}$ (fig.5) is the signatures of homo-coordination system in the AlGa liquid alloys at $1023 \mathrm{~K}$.

The calculated values of $\mathrm{S}_{\mathrm{cc}}(0)$ are used in Eq. (16) to evaluate the ratio of the mutual and intrinsic-diffusion coefficients, $\frac{D_{m}}{D_{i d}}$. Fig.6 shows plot of $\frac{D_{m}}{D_{i d}}$ against the concentration of aluminium. In that plot the value of $\frac{D_{m}}{D_{i d}}$ is found less than 1 in the entire range of concentration of $\mathrm{Al}$, which is indicative for the phase separation in the mixture. A minimum value of $\frac{D_{m}}{D_{i d}}$ $=0.925$ for $c_{I n}=0.5$, confirms a weak tendency for segregation, as observed by the $\mathrm{S}_{\mathrm{cc}}(0)$ and CSRO parameter.

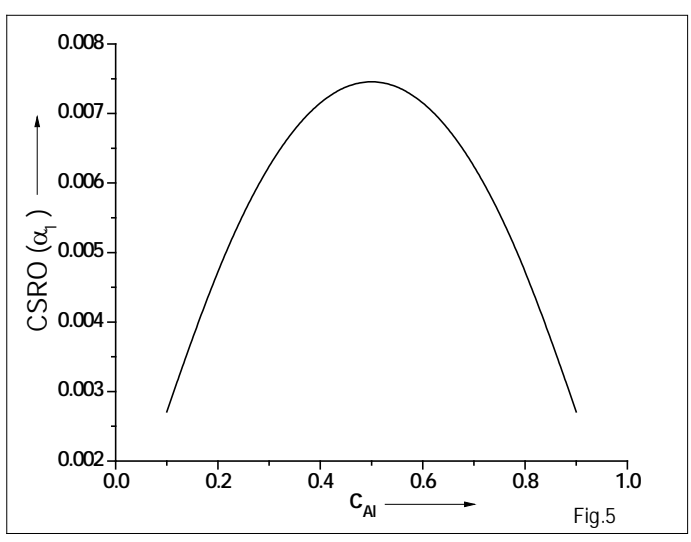

Figure 5: Short range order parameter $\left(\alpha_{1}\right)$ Vs concentration of aluminium $\left(\mathrm{C}_{\mathrm{Al}}\right)$ in liquid $\mathrm{Al}-\mathrm{Ga}$ alloy at $1023 \mathrm{~K}$.

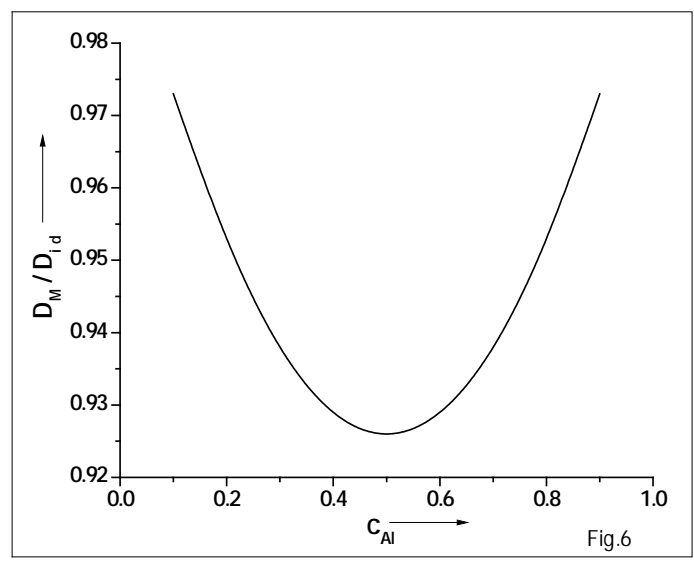

Figure 6: Ratio of chemical and intrinsic diffusion coefficients $\left(D_{M} / D_{i d}\right)$ Vs concentration of aluminium $\left(C_{A l}\right)$ in liquid Al-Ga alloy at $1023 \mathrm{~K}$.

The viscosity of the Al-Ga liquid alloy has been computed numerically from Eq. (15). The plot of $\eta$ verses bulk concentration of $\mathrm{c}_{\mathrm{Al}}$ in Al-Ga liquid alloy is shown in fig.7. In figure, small negative deviations from the linear law (Raoult's law) in viscosity isotherms $\eta(\mathrm{c})$ have been observed for the regular alloy which is the indicative of segregating system.

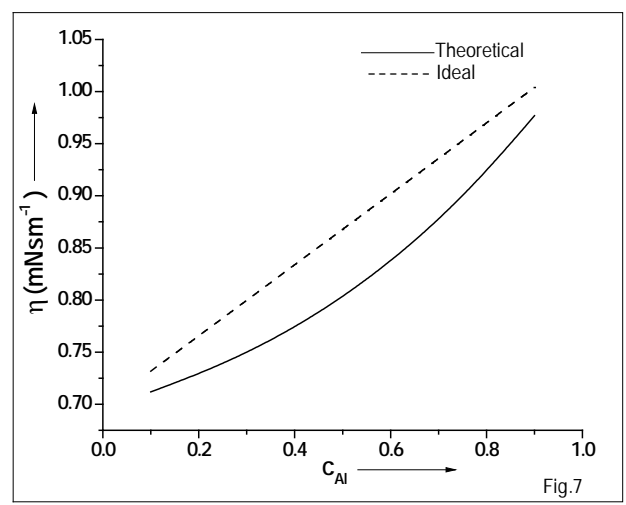

Figure 7:Viscosity $(\eta)$ Vs concentration of aluminium $\left(c_{\mathrm{Al}}\right)$ in liquid Al-Ga alloy at $1023 \mathrm{~K}$. 


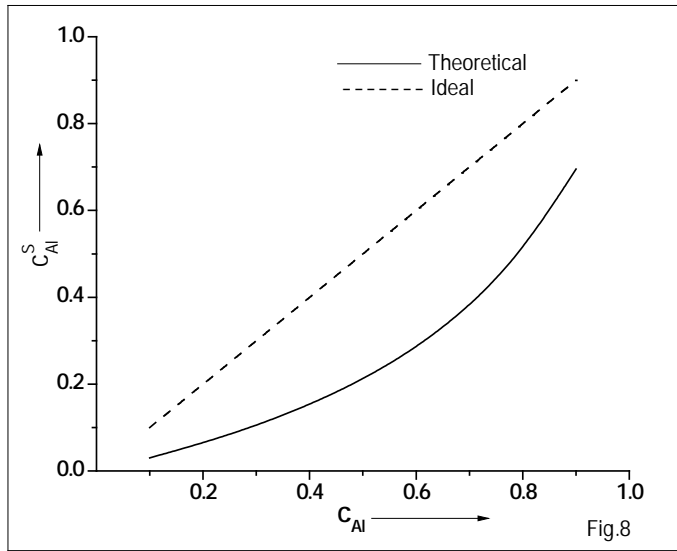

Figure 8: Surface concentration of $\mathrm{Al}\left(\mathrm{c}_{\mathrm{Al}}^{\mathrm{s}}\right) \mathrm{Vs}$ bulk concentration of aluminium $\left(c_{\mathrm{Al}}\right)$ in liquid Al-Ga alloy at $1023 \mathrm{~K}$.

For the computation of surface concentration and surface tension of the Al-Ga alloy on using Butler's approach, the partial excess free energies of mixing of pure components of the alloys have been taken from the ref.(Hultgren et al,1973).By concurrently solving the equations 21(a) and 21(b), surface concentrations of $\mathrm{Al}$ in alloy Al-Ga have been obtained as a function of bulk concentration and then using the obtained values of surface concentrations we computed the surface tension of Al-Ga liquid alloys at temperature $1023 \mathrm{~K}$ for whole concentration range.

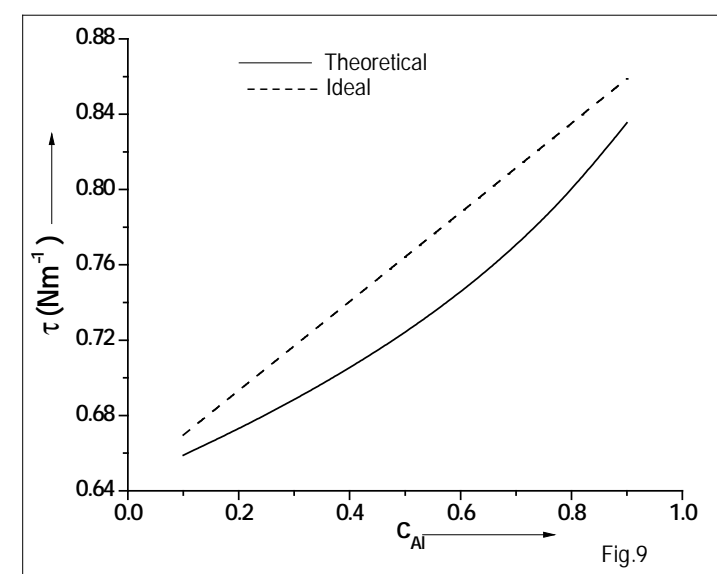

Figure 9: Surface tension $(\tau)$ Vs concentration of aluminium $\left(\mathrm{c}_{\mathrm{Al}}\right)$ in liquid $\mathrm{Al}-\mathrm{Ga}$ alloy at $1023 \mathrm{~K}$.

Figures (8) and (9) are respectively the plots of surface concentration and surface tension against bulk concentration of aluminium in liquid Al-Ga alloys at $1023 \mathrm{~K}$. It is noticed that surface concentration of aluminium in Al-Ga alloys is found to be larger than concentration from additive rule; it increases with increase of its bulk concentrations [Fig.8]. Theoretical analysis gives that the computed surface tension for Al-Ga alloys at $1023 \mathrm{~K}$ is less than ideal values at all concentration of aluminium; i.e. there is negative departure of surface tension from ideality. Butler's approach predicts that surface tension of Al-Ga liquid alloy decreases with increase of bulk concentration of aluminium [Fig.9]. This is an indication that in the alloys there are more atoms of component with bigger atom at the surface. Hence, at the surface of Al-Ga, bigger Gaatoms segregate at the surface in preference to Al-atoms throughout the entire composition. The segregation of the components may result from the differences surface tension, atom radius and electron configuration between solvent and solute.

\section{CONCLUSIONS}

Following conclusions are drawn about liquid Al-Ga alloys at $1023 \mathrm{~K}$ :

1) Order energy is small, positive and found to temperature dependent.

2) The alloy is of a weakly interacting nature.

3) It is of phase-segregating system.

4) Positive departure of thermodynamic and structural parameters from ideality is observed.

5) Viscosity and surface tension isotherm of the alloy is found to deviate negatively from ideality.

6) The surface of liquid Al-Ga alloys is enormously rich with bigger $\mathrm{Ga}$ atoms.

\section{ACKNOWLEDGEMENT}

One of the authors (I.Koirala) acknowledge to Prof. Dr. Lok Narayan Jha and Prof. Dr. Devendra Adhikari (M.M.A.M.C., Biratnagar, Tribhuvan University, Nepal) for their fruitful suggestions and inspiring discussions.

\section{REFERENCES}

Adhikari, D., Singh, B.P. and Jha, I.S. 2012. Transport and surface properties of molten Al-Mn alloy. Adv.Mat.Lett. 3(3): 226-230.

Alonso, J. A. and March, N. H. 1982. Concentration fluctuations in metallic liquid alloys. Physica B. 114: 67.

Anusionwu, B.C. 2002. A theoretical investigations of chemical association in Li-Mg liquid alloy. Physica B. 311: 272.

Bernu, B., Hansen, J.P., Hiwatari, Y. and Pastore, G. 1987. Soft sphere model for the glass transition in binary alloys, pair structure and self diffusion. Phys. Rev. A 36: 4891

Bhatia, A. B., Hargrove, W. H. and March, N. H. 1973. Concentration fluctuations in conformal solution and partial structure factor in alloys. J. Phys.C: solid state physics. 6: 621 .

Campbell, F. C., Ed. 2008. Elements of metallurgy and engineering alloys. ASM International.

Cowley, J. M. 1950. An approximate theory of order in alloys. Phys. Rev. 77: 669 .

Darken, L. S. and Gurry, R. W. 1953.Physical chemistry of metal. McGraw Hill,New York. 535.

Faber, T. E. 1972. Introduction to the theory of liquid metals. Cambridge Univ. Press, Cambridge.

Flory, J. 1942. Thermodynamics of high polymer solutions. J. Chem. Phys. 10: 51.

Guggenheim, E. A. Mixture. 1952. Oxford University Press, London. 
Harada, S., Takahashi, S., Takeda, S., Tamaki, S., Grey, P. and Cusack, N. E. 1988. Thermodynamic Properties of Liquid Na-Cd and Na-In . J. Phys. F. 18: 2559.

Harrision W. A. 1966. Pseudopotential in the Theory of metal, W.A.Benjamin,Inc.,New York.

Hultgren, R., Desai, P.D., Hawkins, D.T., Gleiser, M., Kelley, K.K. 1973. Selected Values of the Thermodynamic Properties of Binary Alloys. ASM Metals Park, Ohio. 1013.

Butler J. A. V. 1932. Thermodynamics of surface solution. Proc.R.Soc.A.135: 348.

Iida, T. and R.I.L. Guthrie. 1988. The physical properties of liquid metals. Clarendon Press; Oxford. J. Non-Cryst. Solids 61-62: 279.

Koirala, I., Jha, I. S., Singh, B. P., Adhikari, D. 2013. Thermodynamic, transport and surface properties in In-Pb liquid alloys. Physica B. 423: 49.

Lamparter, P., Martin, W., Steeb, S. and Freyland, W. 1984. Local Order in Liquid Potassium-Antimony Alloys Studied by Neutron Diffraction . J. Non-Cryst. Solids 61-62: 279.

Lebowitz, J. L. 1964. Exact solution of generalised Percus-Yevick equation for mixture of hard spheres. Phys. Rev. 133: A895.

Li, W. and Tosi, M. P. 1989. Electron theory of long-wavelength concentration fluctuations in liquid metal alloys. Il Nuovo Cim. 11(10): 1509 .

Novakovic, R. Thermodynamics, surface properties and microscopic functions of liquid Al-Nb and Nb-Ti alloys. 2010. J.Non-Cryst.Solids. 356: 1593 .

Saboungi, M. L., Marr, J. and Blander, M. 1978. Thermodynamic Properties of a Quasi-ionic Alloy from Electromotive Force Measurements : the Li-Pb System . J. Chem. Phys. 68: 1375.

Shimoji, M. 1977. Liquid metals. London Acad., London.

Singh, R. N. 1987. Short range order and concentration fluctuations in binary molten alloys.Can.J.Phys. 34: 249.

Singh, R. N., Mishra, I. K. and Singh, V. N. 1990. Local order in Cdbased liquid alloys. Phys.Condens. Matter. 2: 8457.

Singh, R. N., Jha, I. S. and Sinha, S.K. 1993.The segregation-order transformation in Cd-Na liquid alloy. J. Phys. Condens.Matter. 3: 2787.

Warren, B. E. 1996. X-ray Diffraction. Addison-Wesle, Reading MA. 227.

Woodall, J. M., Ziebarth, J. and Allen, C. R. 2007. The science and technology of Al-Ga alloys as a material for energy storage, transport and splitting water. Proc. of $2^{\text {nd }}$ energy nanotechnology international conference,ENIC,450140. 